\title{
Quercetin in prostate cancer: Chemotherapeutic and chemopreventive effects, mechanisms and clinical application potential (Review)
}

\author{
FEIYA YANG ${ }^{1}$, LIMING SONG $^{1}$, HUIPING WANG $^{2}$, JUN WANG $^{3}$, ZHIQING XU $^{4}$ and NIANZENG XING ${ }^{1}$ \\ ${ }^{1}$ Department of Urology, Beijing Chaoyang Hospital, Capital Medical University, Beijing 100020; \\ ${ }^{2}$ Department of Reproductive Immunology and Pharmacology, National Research Institute \\ for Family Planning, Beijing 100081; ${ }^{3}$ Department of Neurosurgery, The First Hospital \\ of China Medical University, Shenyang, Liaoning 110001; ${ }^{4}$ Institute of Neuroscience, \\ Beijing Key Laboratory of Neural Regeneration and Repair, \\ Capital Medical University, Beijing 100069, P.R. China
}

Received January 8, 2015; Accepted March 9, 2015

DOI: $10.3892 /$ or.2015.3886

\begin{abstract}
The morbidity and mortality of prostate cancer have been increasing recently, and the comprehensive treatment for prostate cancer is unable to achieve satisfactory outcomes. Quercetin is a natural flavonoid compound that has attracted increased interest and attention due to its anticancer activity. In vitro and in vivo studies have verified that quercetin effectively inhibits prostate cancer via various mechanisms. Clinical trails concerning the pharmacokinetics and application of quercetin in humans have also obtained promising results. Meanwhile, epidemiologic studies have demonstrated a negative association between quercetin intake and prostate cancer incidence and have suggested a chemopreventive effect of quercetin on prostate cancer that has been exhibited in animal experiments. The main issue concerning quercetin utilization is its low bioavailability. Therefore, solutions to the issues concerning its use such as alteration of the molecular structure and combination therapy are in the exploratory stage. In the present review, the most important aspects of chemotherapeutic and chemopreventive effects, mechanisms and clinical application potential of quercetin in prostate cancer are summarized.
\end{abstract}

\section{Contents \\ 1. Introduction \\ 2. Prostate cancer \\ 3. Quercetin}

Correspondence to: Professor Nianzeng Xing, Department of Urology, Beijing Chaoyang Hospital, Capital Medical University, 8 Gongren Tiyuchang Nanlu, Beijing 100020, P.R. China

E-mail: xingnianzeng@126.com

Key words: prostate cancer, chemotherapy, chemoprevention, effect, mechanisms, quercetin, clinical application potential
4. In vitro and in vivo anti-prostate cancer effects of quercetin 5. Molecular mechanisms of the anti-prostate cancer effects

6. Deficiency and improved measures

7. Chemopreventive effects and relevant mechanisms

8. Clinical trails

9. Clinical application potential of quercetin for prostate cancer 10. Conclusion

\section{Introduction}

The morbidity and mortality associated with prostate cancer have been gradually increasing and the treatment of castration-resistant prostate cancer (CRPC) shows disappointing outcomes $(1,2)$; thus researchers are searching for novel effective substances and striving to change this unfavorable condition. Quercetin is a natural flavonoid compound which has been shown to effectively inhibit prostate cancer growth. Our previous studies also found that quercetin antagonizes prostate cancer by reducing androgen receptor (AR) expression, by inducing apoptosis and by suppressing proliferation $(3,4)$. Recently, the chemopreventive effects of quercetin on prostate cancer have aroused the interest of researchers and have been demonstrated in animal experiments (5-7). In consideration of all the inspiring results, the promising aspects of quercetin in the treatment of prostate cancer are summarized in the following review.

\section{Prostate cancer}

Prostate cancer is a common male malignant disease and its incidence is increasing worldwide, with an estimated 233,000 new cases and 29,480 deaths in 2014 in the United States. The incidence rate of new cases is $27 \%$ occupying the first place and the mortality rate is $10 \%$ occupying the second place only inferior to lung cancer among body sites where tumorigenesis may occur (1). When prostate cancer is confined and does not invade the capsule or metastasize, it can be cured 
by radical prostatectomy and radiation. Even so, most patients later suffer from local recurrence and bone or other organ metastasis (8). Concerning these patients, androgen deprivation therapy (ADT) is usually effective at the beginning. But after a median time of $18-24$ months, it progresses to a more aggressive stage, namely CRPC characterized by progression during ADT, continuous increase in serum prostate-specific antigen (PSA), and emergence of new metastatic lesions. Currently, first-line systemic chemotherapy for CRPC is the combined use of docetaxel and prednisone (9). However, this therapeutic regimen is not curative, and cannot prolong overall survival to a large degree as compared with previous combination or single-drug treatment, and it confers severe side effects to patients (10). In order to overcome this adversity, researchers have assessed novel therapeutic substances and strategies such as CYP17 inhibitor, AR inhibitor and drug combination treatment which exhibit additive or synergistic effects in vitro. But when combined with docetaxel, no improvement was gained $(2,11,12)$. For this reason, it is of great need to obtain more effective and low toxic substances to alter the present unsatisfactory situation.

\section{Quercetin}

Quercetin (3,3',4',5,7-pentahydroxyflavone, Que) is a bioactive plant-derived flavonoid, abundant in fruits and vegetables particularly in onions, apples, red wine and tea. Daily human intake of quercetin ranges from 10 to $100 \mathrm{mg}$ depending on different dietary habits, and it can reach 500-1,000 $\mathrm{mg}$ if selected highly purified extracts are used (13). Under normal circumstances, quercetin exists in plants in the form of hydrophilic glycosides which means that it cannot be directly and easily absorbed. Moreover, the plant matrix is also the pivotal factor affecting the absorption rate and extent (14). In vivo studies in humans demonstrated that after being absorbed by the small intestine, quercetin glycosides are hydrolyzed leading to an increased absorption rate of quercetin aglycone as high as $65-81 \%$ and it is bacteria-enzyme independent (15). Then quercetin is first metabolized including glucoronidation, methylation or sulphation in order to form its main conjugates: 3- $O$-methyl-quercetin (isorhamnetin), quercetin-3- $O$-glucuronide (Q3GlcA) and isorhamnetin 3-O-glucuronide. The whole metabolic process is terminated in the liver where it possesses all the necessary enzymatic systems for quercetin metabolism. Kidney, colon and large intestine also participate in the metabolic process of quercetin $(13,16)$.

In recent years, more and more research has shown the anticancer property of quercetin in a variety of human cancer cell lines both in vitro and in vivo such as cervical, breast, colon (17) and lung carcinoma (18) and prostate cancer (19). Quercetin can effectively inhibit the growth of many types of tumors and is non-toxic. Moreover, it is abundant in fruits and vegetables and can be sufficiently obtained through the daily diet. Thus, there exist broad application prospects for quercetin in cancer treatment including prostate cancer.

\section{In vitro and in vivo anti-prostate cancer effects of quercetin}

Considering the dismal situation in treatment for prostate cancer and the inspiring results of the anticancer effects of quercetin, it has been used in a series of studies on human prostate cancer and has exhibited favorable effects. When used in vitro, whether alone or in combination, quercetin greatly arrests the cell cycle, decreases cell viability, inhibits proliferation and induces cell apoptosis. Table I summarizes the in vitro effects of quercetin on prostate cancer. Similarly, when used in vivo, quercetin inhibits prostate cancer cell xenograft tumor growth effectively at the selective dose. Relevant results are summarized in Table II.

\section{Molecular mechanisms of the anti-prostate cancer effects}

Tumorigenesis is a complicated process involving the alteration of many signaling pathways and numerous molecular dysfunctions. It has been suggested that targeted therapy for these variations using natural products and phytochemicals is promising (20). Quercetin, as a natural flavonoid, can act on target changes in prostate cancer and exhibit favorable anticancer effects. Mechanisms of the in vitro and in vivo effects of quercetin on prostate cancer are summarized in Tables I and II.

Mechanisms of the in vitro effect

Inhibition of proliferation. Cell mitosis and proliferation play an important role in the progression of tumors. Hence, cell cycle arrest and proliferation inhibition are effective measures for cancer treatment. Quercetin can play this role in prostate cancer. We explored the effect of quercetin on the proliferation of human prostate cancer PC-3 and LNCaP cells treated with varying doses and found that the inhibition rate demonstrated a dose-dependent increase. $\mathrm{IC}_{50}$ values of quercetin were found to be $22.12 \mu \mathrm{M}$ for PC-3 and $23.29 \mu \mathrm{M}$ for $\mathrm{LNCaP}$ cells. Quercetin treatment not only resulted in an increase in the G2/M phase population in both PC-3 and LNCaP cells, but also increased the $\mathrm{S}$ phase population in PC-3 cells (4).

Liu et al treated human prostate cancer PC-3 cells with quercetin at various doses $(50-200 \mu \mathrm{M})$ for 24 and $48 \mathrm{~h}$ and found that cell viability was significantly decreased in a timeand dose-dependent manner. It was attributed to induction of G0/G1 (31.4-49.7\%) and sub-G1 (19.77\%) cell cycle arrest which was caused by downregulation of cyclin D and E, CDK2, cdc25c and upregulation of p21, p53, p18 and p27 (21). In PPC1 prostate carcinoma cells, quercetin at a high dose arrested the cell cycle and inhibited proliferation. However, the p53 status should be taken into consideration (22). Quercetin also displayed proliferation inhibition in a dose-dependent manner in PC-3 cells at a non-cytotoxic concentration, during which endoplasmic reticulum (ER)-mediated and ER-independent pathways as well as cell cycle inhibition induced by cyclin D1 and E downregulation may be the vital factors (23). Other studies obtained the same results for quercetin and suggested that anti-proliferation was achieved through modulation of NO production (24-27).

Induction of apoptosis. Apoptosis is defined as programmed cell death and plays an important role in maintaining stabilization of cell homeostasis. It is divided into death receptor (DR)-mediated extrinsic and mitochondrial-mediated intrinsic pathways, and they both activate the common 'executor' caspase-3 leading to cell apoptosis. As insufficient apoptosis is 
Table I. In vitro effects and mechanisms of quercetin in prostate cancer.

\begin{tabular}{|c|c|c|}
\hline Cells & Effects and mechanisms & Ref. \\
\hline PC-3 and LNCaP & Inhibits proliferation, cell cycle arrest, induces apoptosis & (4) \\
\hline PC-3 & Inhibits proliferation, cell cycle arrest, endoplasmic reticulum stress, mitochondrial apoptosis & $(21)$ \\
\hline PPC1 & Inhibits proliferation, cell cycle arrest, p53 status & (22) \\
\hline PC-3 & $\begin{array}{l}\text { Inhibits proliferation, cell cycle arrest, induces apoptosis, reduces pAKT level, decreases ERK-1/2, } \\
\text { increases JNK }\end{array}$ & $(23)$ \\
\hline PC-3 & Inhibits proliferation & $(24)$ \\
\hline PC-3 and LNCaP & Inhibits proliferation, cell cycle arrest & $(25)$ \\
\hline PC-3 & Inhibits proliferation, alters cell cycle progression & (26) \\
\hline PC-3, LNCaP and DU-145 & Inhibits proliferation, modulates NO production & (27) \\
\hline DU-145 & Upregulates death receptor 5 , enhances extrinsic apoptosis mediated by TRAIL & (29) \\
\hline PC-3 and DU-145 & $\begin{array}{l}\text { Enhances TRAIL-induced apoptosis, downregulates survivin, } \\
\text { deacetylation of histone } \mathrm{H}-3 \text { mediated by ERK }\end{array}$ & $(30)$ \\
\hline LNCaP and DU-145 & Enhances TRAIL-induced apoptosis, dephosphorylation of AKT & $(31)$ \\
\hline LNCaP & Promotes apoptosis, reduces pAKT level & $(32)$ \\
\hline PC-3 & $\begin{array}{l}\text { Induces extrinsic and intrinsic apoptosis, reduces pAKT level, decreases IGF-I, -II, -IR mRNA } \\
\text { and IGF-IR } \beta \text { protein }\end{array}$ & $(33)$ \\
\hline PC-3 & Inhibits proliferation, induces apoptosis & $(34)$ \\
\hline PC-3 and LNCaP & Inhibits proliferation, cell cycle arrest, induces apoptosis & $(35)$ \\
\hline PC-3 & $\begin{array}{l}\text { Inhibits proliferation, induces apoptosis, increases p } 21 \text { and hypophosphorylated } \\
\text { retinoblastoma proteins }\end{array}$ & (36) \\
\hline PC-3 and LNCaP & Induces apoptosis & $(37)$ \\
\hline $\mathrm{LNCaP}$ & Induces formation of c-Jun/Sp1/AR protein complex and impairs function of AR & $(42)$ \\
\hline LNCaP & Inhibits expression and function of AR & (3) \\
\hline LNCaP & Reduces expression of AR, inhibits proliferation, induces apoptosis & (43) \\
\hline $\begin{array}{l}\text { Human-derived prostate } \\
\text { cancer cell line } 22 \mathrm{Rv} 1\end{array}$ & Modulates AR signaling pathway and impairs AR function & (47) \\
\hline LNCaP & Induces overexpression of c-Jun, inhibits expression and function of AR & $(44)$ \\
\hline LNCaP & Direct association of c-Jun and AR, impairs AR function & $(45)$ \\
\hline CWR22Rv1 prostate cancer cells & Reduces AR expression, increases p53, NQO1 and NQO2 & $(48)$ \\
\hline LNCaP & Retards DNA synthesis, decreases AR expression & (49) \\
\hline LNCaP & Inhibits AR involving transcription factor $\mathrm{Sp} 1$ & (46) \\
\hline $\begin{array}{l}\text { Androgen-independent } \\
\text { prostate cancer C4-2 cells }\end{array}$ & Inhibits PI3K/AKT signal pathway, induces apoptosis & $(52)$ \\
\hline PC-3 & $\begin{array}{l}\text { Reduces pAKT level, inhibits angiogenesis and VEGF secretion } \\
\text { via AKT/mTOR/P70S6K pathway }\end{array}$ & $(53)$ \\
\hline LNCaP & Inhibits angiogenesis, decreases HIF- $1 \alpha$ accumulation and VEGF secretion & $(61)$ \\
\hline $\mathrm{PC}-3$ & Increases p38-MAPK, inhibits survival and proliferation, inhibits uPA and its receptor & $(66)$ \\
\hline PC-3 & Increases IGFBP-3, induces apoptosis & $(69)$ \\
\hline PC-3 & Increases IGFBP-3, decreases IGFs, induces apoptosis & $(70)$ \\
\hline $\begin{array}{l}\text { AT6.3 rat prostate cancer } \\
\text { cell line }\end{array}$ & Reduces insulin like growth factor- 1 & (71) \\
\hline PC-3 & $\begin{array}{l}\text { Reverses EMT, decreases EGF-induced transcriptional repressors, } \\
\text { inhibits EGFR/PI3K/AKT/ERK1/2 }\end{array}$ & $(72)$ \\
\hline Prostate cancer stem cells & $\begin{array}{l}\text { Inhibits EMT, reduces vimentin, Slug, Snail, nuclear } \beta \text {-catenin activity, inhibits proliferation, } \\
\text { induces apoptosis }\end{array}$ & $(73)$ \\
\hline PC-3 & Interacts with heterogeneous nuclear ribonucleoprotein & (74) \\
\hline PC-3 & Inhibits transcriptional activity of $\mathrm{COX}-2$ promoter mediated by $\mathrm{NF}-\kappa \mathrm{B}$, induces apoptosis & (75) \\
\hline TRAMP-C2 & Hedgehog signaling pathway & (76) \\
\hline PC-3 and DU-145 & Increases tumor-suppressor genes, reduces oncogenes and cell cycle genes & (77) \\
\hline PC-3 & Immune therapy, stimulates GM-CSF secretion & (78) \\
\hline PC-3, LNCaP and DU-145 & Reduces levels of heat shock protein (Hsp) 90, inhibits proliferation, induces apoptosis & (79) \\
\hline PC-3 & Depletion of HSP70 & $(80)$ \\
\hline PC-3, Lncap and JCA-1 & Decreases HSP70 & $(81)$ \\
\hline PC-3 and DU-145 & Decreases HSP72 & $(82)$ \\
\hline PC-3 & Downregulates matrix metalloproteinases 2 and 9 & (83) \\
\hline $\begin{array}{l}22 \mathrm{Rv} 1 \text { human prostate } \\
\text { cancer cells }\end{array}$ & Inhibits CYP1 cytochrome P450 enzymes & $(84)$ \\
\hline $\mathrm{LNCaP}$ & Inhibits fatty acid synthase activity & $(85)$ \\
\hline PC-3 and $\mathrm{LNCaP}$ & Inhibits ErbB-2 and ErbB-3 expression, inhibits proliferation & (86) \\
\hline
\end{tabular}
to mesenchymal transition; COX, cyclooxygenase; NF- $\mathrm{kB}$, nuclear factor; GM-CSF, granulocyte-macrophage colony-stimulating factor; Hsp, heat shock protein. 
Table II. In vivo effects and mechanisms of quercetin in prostate cancer.

\begin{tabular}{|c|c|c|c|c|}
\hline Cells & Experimental animals; and effects & Dose of quercetin & Mechanism & Ref. \\
\hline PC- 3 cells & $\begin{array}{l}\text { Male BALB/c nude mice; } \\
\text { inhibits xenograft tumor growth }\end{array}$ & $20 \mathrm{mg} / \mathrm{kg} /$ day & Inhibits angiogenesis & $(53)$ \\
\hline $\begin{array}{l}\text { Androgen-sensitive } \\
\text { LAPC- } 4 \text { prostate } \\
\text { cancer cells }\end{array}$ & $\begin{array}{l}\text { Male SCID mice; } \\
\text { inhibits xenograft } \\
\text { tumor growth }\end{array}$ & $0.4 \%$ quercetin diet & $\begin{array}{l}\text { Induces apoptosis, } \\
\text { inhibits proliferation, } \\
\text { pAKT, PSA and AR }\end{array}$ & $(88)$ \\
\hline \multirow[t]{2}{*}{$\begin{array}{l}\text { CWR22 prostate } \\
\text { tumor cells }\end{array}$} & $\begin{array}{l}\text { Severe combined immune } \\
\text { deficient (SCID) mice; inhibits xenograft } \\
\text { tumor growth }\end{array}$ & $200 \mathrm{mg} / \mathrm{kg}$ & $\begin{array}{l}\text { Inhibits proliferation } \\
\text { and angiogenesis }\end{array}$ & $(87)$ \\
\hline & $\begin{array}{l}\text { Male Sprague-Dawley rats; } \\
\text { reduces wet prostate weight }\end{array}$ & 50,100 or $150 \mathrm{mg}$ & $\begin{array}{l}\text { Inhibits proliferation, } \\
\text { reduces phospho-MEK 1/2 } \\
\text { and phospho-MAPK, } \\
\text { increases } \mathrm{p} 15, \mathrm{p} 21 \text { and } \mathrm{p} 27\end{array}$ & (89) \\
\hline PC-3 and DU-145 & $\begin{array}{l}\text { Male nude mice; } \\
\text { inhibits xenograft tumor growth }\end{array}$ & $150 \mathrm{mg} / \mathrm{kg}$ & Inhibits HSP72 & $(82)$ \\
\hline
\end{tabular}

pAKT, phosphorylated AKT; PSA, prostate-specific antigen; AR, androgen receptor; MAPK, mitogen-activated protein kinase; MEK, mitogen extracellular kinase; Hsp, heat shock protein.

a critical cause of tumorigenesis, many drugs treat cancers by inducing apoptosis (28). We conducted research to investigate the effect of quercetin on PC-3 and LNCaP cells and found that quercetin induced apoptosis by increasing pro-apoptotic Bax and by decreasing anti-apoptotic Bcl-2 protein resulting in a significant decrease in the Bcl-2/Bax ratio (4).

After PC-3 cells were treated with quercetin, in addition to a decrease in anti-apoptotic Bcl-2 and an increase in pro-apoptotic Bax, ER stress-associated proteins such as GRP78, ATF-4 $\alpha$ and IRE-1 $\alpha$ were also increased, followed by direct activation of the caspase cascade leading to subsequent apoptosis through the mitochondrial pathway and ER stress (21). Quercetin was found to enhance extrinsic apoptosis mediated by tumor necrosis factor-related apoptosis-inducing ligand (TRAIL) in DU-145 cells either through DR5 upregulation (29) or survivin downregulation via deacetylation of histone H-3 mediated by ERK in PC-3 and DU-145 cells (30) or dephosphorylation of AKT in LNCaP and DU-145 cells (31).

From the previously published studies, it can be concluded that quercetin induces apoptosis of prostate cancer mainly by regulating Bax, Bcl-2 and the Bcl-2/Bax ratio, namely through mitochondrial-mediated intrinsic pathway, and it can also mediate the extrinsic pathway $(23,32,33)$. Induction of apoptosis in various types of prostate cancer cells by quercetin which may be the main property of its anti-prostate cancer effects has been widely studied and is gaining more and more recognition (34-37).

Inhibition of the androgen receptor $(A R)$. AR, a nuclear receptor belonging to a superfamily of ligand responsive transcription, regulates physiological actions of androgen (38) and is nearly expressed in all types of prostate cancer (39). Since the relationship of AR and the development and progression of prostate cancer has been verified, targeted therapy of AR is now considered as a promising measure for controlling prostate cancer progression (40-42). We treated LNCaP cells with quercetin and found that AR protein was reduced in a dose-dependent manner after a designated time. Moreover, the regulated tumor markers, PSA and hK2, were inhibited, and regulated genes such as PSA, NKX3.1 and ornithine decarboxylase (ODC) mRNA were downregulated. These findings indicate that quercetin not only decreases AR expression but also impairs the function of AR and has the potential to serve as a chemotherapeutic drug for prostate cancer (3).

Quercetin treatment reduced expression of $\mathrm{AR}$ and then increased caspase-3/-7 causing subsequent anti-proliferation and apoptosis in LNCaP cells (43). It also reduced expression and impaired the function of AR through c-Jun or Sp1 which either interacted directly with AR or formed c-Jun/Sp1/AR protein complex $(42,44-46)$. Other anti-prostate cancer functions of quercetin through AR include retardation of DNA synthesis and modulation of the AR signaling pathway. The common findings included decreased expression and impaired function of AR and finally, the inhibition of prostate cancer growth (47-49).

Inhibition of phosphatidylinositol 3-kinase (PI3K)/AKT signaling pathway. The PI3K/AKT signaling pathway is upregulated in 30-50\% of prostate cancer cases. When phosphorylated at serine 473 , AKT is activated into phosphorylated AKT (pAKT) which plays a vital role in the proliferation, survival and progression of prostate cancer and helps inhibit apoptosis by phosphorylating downstream substrates (50). Recent research reported that in the progression from androgen-dependent to androgen-independent status, the PI3K/AKT signaling pathway may be of great importance. Even though androgen is at a very low level, it can maintain the high proliferation of prostate cancer cells (51). Therefore, it is speculated that PI3K/AKT inhibitors can effectively treat prostate cancer.

Recently, a latent PI3K inhibitor prodrug was generated using a quercetin analog and a peptide that could cleave PSA. When the inhibitor was activated, the PI3K/AKT signaling pathway was inhibited and apoptosis was induced resulting in 
the cell death of androgen-independent prostate cancer C4-2 cells that could secret PSA (52). In PC-3 cells, quercetin significantly reduced pAKT levels and reversed its anti-apoptotic effect preventing tumor cells from infinite proliferation. The results were the same for LNCaP and DU-145 cells (23,31-33). In addition, the AKT signaling pathway was found to contribute to angiogenesis. Yet, when it was suppressed by quercetin, angiogenesis was effectively suppressed (53).

Inhibition of angiogenesis. Angiogenesis is the process of new blood vessel formation from the pre-existing vascular system and is regulated by two angiogenic factors: vascular endothelial growth factor (VEGF) and hypoxia inducible factor (HIF) $\alpha$ (54). Blood vessels are abundant in tumor tissues as tumors themselves can induce neovascularization. This provides tumors with enough oxygen and nutrients and ensures their development and progression (55-57). Anticancer drugs inhibit angiogenesis by targeting angiogenic factors $(58,59)$.

We administered varying doses $(0-100 \mu \mathrm{M})$ of quercetin to a rhesus choroid-retina endothelial cell line (RF/6A) and found that endothelial cell proliferation, migration and tube formation were significantly inhibited after incubation for 24 , 48 and $72 \mathrm{~h}$. Our experimental results concluded that quercetin inhibited angiogenesis in vitro (60). Pratheeshkumar et al carried out in vitro and ex vivo experiments to examine the effect of quercetin on angiogenesis and showed that quercetin not only greatly inhibited angiogenesis in vitro by influencing the critical processes of proliferation, migration, invasion and tube formation of endothelial cells, but also inhibited angiogenesis ex vivo via reducing vascularized structure and microvessel outgrowth. When PC-3 cells were treated with quercetin, VEGF secretion and cell viability were markedly decreased in a dose-dependent manner, and this occurred by having a negative impact on the AKT/mTOR/P70S6K pathway (53). As for LNCaP cells, quercetin inhibited angiogenesis by decreasing HIF-1 $\alpha$ accumulation and VEGF secretion (61).

Regulation of the ERK-1/2/JNK/MAPK signaling pathway. ERK-1/2, JNK and p38-MAPK are the three most important components of the MAPK signaling pathway (62). In prostate cancer, the ERK pathway is activated and is associated with advanced stages and high invasive property $(63,64)$. JNK and p38 play an important role in promoting apoptosis and negatively regulating tumor cell growth (65). Quercetin treatment in PC-3 cells decreased the ERK-1/2 level and increased JNK expression by which cancer apoptosis was prompted and tumor growth was inhibited (23). As another important component of the MAPK signaling pathway, p38-MAPK was increased by quercetin in PC-3 cells contributing to the inhibition of cancer survival and proliferation (66).

Inhibition of the insulin-like growth factor (IGF) signaling pathway. The IGF/IGF-R axis is regarded as a critical element in the initiation and development of prostate cancer, and overexpression of insulin receptor in human prostate cancer has been identified (67). Androgen-independence and progression of prostate cancer are related with IGF/IGF-R overexpression (68). Quercetin decreased IGF-I, IGF-II, IGF-IR mRNA and IGF-IR $\beta$ protein in PC-3 cells and could be used for androgen-independent prostate cancer treatment (33). Another two studies showed that quercetin increased insulin-like growth factor-binding protein-3 (IGFBP-3) which had high binding affinity with IGFs causing marked reduction. In this manner, the $\mathrm{Bax} / \mathrm{Bcl}-2$ protein ratio was modulated and apoptosis was induced via a p53-independent manner (69,70). Moreover, in the AT6.3 rat prostate cancer cell line, quercetin acted via a reduction in insulin-like growth factor-1 (71).

Reversal of epithelial-to-mesenchymal transition (EMT) and invasiveness induced by epidermal growth factor (EGF). EGF can promote EMT in tumors making them acquire high invasiveness and this also occurs in prostate cancer suggesting the pivotal role of EGF in mediating progression and metastasis of prostate cancer. Bhat $e t$ al showed that quercetin reversed EMT in PC-3 cells induced by EGF which prevented tumor cells from invading and migrating. This was achieved through a decrease in EGF-induced transcriptional repressors such as Snail, Slug and Twist and inhibition of the EGFR/PI3K/AKT/ ERK1/2 pathway (72). Tang et al also demonstrated that quercetin inhibited EMT and expression of related molecules (73). Therefore, targeting EGF by quercetin can effectively prevent prostate cancer from metastasizing.

Heterogeneous nuclear ribonucleoprotein Al (hnRNPAl). Quercetin binds with the C-terminal region and interacts with hnRNPA1 leading to cytoplasmic retention manifested as abnormal shuttle between the nucleus and cytoplasm, which greatly impairs the function of hnRNPA1 and inhibits PC-3 cell growth (74).

Other molecular mechanisms involved. Apart from the possible mechanisms elaborated above involved in quercetin treatment of different prostate cancer cell lines, there also exist other mechanisms reported by researchers.

Quercetin inhibited nuclear factor (NF)- $\mathrm{BB}$-mediated transcriptional activity of COX-2 promoter (75) and acted on urokinase-type plasminogen activator (uPA) and its receptor resulting in inhibition of factors related to survival and proliferation in PC-3 cells (66). Quercetin restrained prostate cancer stem cells isolated from PC-3 and LNCaP cells from invading and migrating (73). Quercetin also used Hedgehog signaling pathway as a direct or indirect target to antagonize TRAMP-C2 cells (76), increased tumor suppressor p53 (48), downregulated oncogenes and cell cycle genes (77), and stimulated granulocyte-macrophage colony-stimulating factor (GM-CSF) secretion causing immune therapy in PC-3 cells (78).

What is more, quercetin also reduced heat shock protein (Hsp) 90, 70 and 72 expression (79-82), downregulated matrix metalloproteinases 2 and 9 protein (83), inhibited CYP1 cytochrome P450 enzymes (84) and fatty acid synthase activity (85), and ErbB-2 and ErbB-3 expression (86) in prostate cancer cell lines.

Mechanisms of the in vivo effect. Contrary to many in vitro studies, there are only a few in vivo studies of quercetin on prostate cancer. However, quercetin has begun to be used in vivo and these preclinical results will lay a good foundation for subsequent clinical trails.

Inhibition of angiogenesis. Pratheeshkumar et al injected $5 \times 10^{6} \mathrm{PC}-3$ prostate cancer cells into male 6 -week-old BALB/c nude mice. When the tumor volume reached $\sim 100 \mathrm{~mm}^{3}$, the mice in the treatment group received quercetin at $20 \mathrm{mg} / \mathrm{kg} / \mathrm{day}$ intraperitoneally. Treatment with quercetin significantly inhibited tumor growth as compared to the vehicle control 15 days later. Western blot and immunohistochemical analyses 
exhibited that quercetin inhibited angiogenesis through the AKT/mTOR/P70S6K signaling pathway mediated by VEGFR-2 (53). Ma et al used CWR22 prostate cancer cell xenograft tumors to evaluate the therapeutic effect of quercetin and found that quercetin at $200 \mathrm{mg} / \mathrm{kg}$ reduced tumor volume by $51.1 \%$, which was due to a decrease in VEGF121 and VEGF165 that negatively regulated vascular formation (87).

Induction of apoptosis, inhibition of proliferation, pAKT, $P S A$ and $A R$. After intervention of a $0.4 \%$ quercetin diet for 6 weeks, the growth of androgen-sensitive LAPC-4 prostate cancer cell xenograft tumors in male SCID mice was inhibited by $15 \%$. Subsequent biomarker analysis revealed that this was attributed to apoptosis induction represented as increased Bax and Bax/Bcl-2 ratio, proliferation inhibition manifested as decreased Ki67, and downregulation of pAKT, PSA and AR (88). Ma et al also demonstrated tumor inhibition by quercetin at the dose of $200 \mathrm{mg} / \mathrm{kg}$ which they attributed to proliferation suppression caused by modulation of the phosphorylation of cdc- 2 and cyclin $\mathrm{Bl}$ (87). The same effectiveness and mechanism were observed in another study using 50, 100 or $150 \mathrm{mg}$ of quercetin to reduce prostate weight in male Sprague-Dawley rats. Phospho-MEK1/2, phospho-MAPK, p15, p21 as well as p27 were also involved (89).

Inhibition of HSP72. When quercetin at $150 \mathrm{mg} / \mathrm{kg}$ was administered intraperitoneally in prostate cancer PC-3 and DU-145 xenograft tumor models, it suppressed xenograft tumor growth attributed to the antagonization of HSP72 expression (82).

\section{Deficiency and improved measures}

Deficiency. Despite the promising application of quercetin for prostate cancer, low bioavailability hampers the effect of anti-prostate cancer to a great extent. Although the plasma concentration of quercetin can be increased by a dietary supplement, it is far from meeting the need. Therefore, effective measures are of urgent demand to be taken for improving the availability of quercetin (13).

Alteration of the molecular structure. At present, concerning the alteration in the molecular structure to increase the availability of quercetin, the most promising and practical method is making a nanocomposite by nanotechnology. Quercetin nanocomposite is composed of 3 parts: flavonoid quercetin, the polymeric part and carbon nanotube (CNT) component $(90,91)$. While quercetin is the biologically active component responsible for its anticancer effect (92), the polymeric part can enhance the water solubility and stability of quercetin, and CNTs can promote interaction with cells $(93,94)$. As a result, the anticancer activity and bioavailability of quercetin are greatly enhanced. The $\mathrm{IC}_{50}$ value of the quercetin nanocomposite was much lower than free quercetin and no toxicity was observed in viability testing on healthy cells (94).

There are also some attempts using modified quercetin analogs in prostate cancer treatment. A chemically modified quercetin analog was coupled with a peptide Mu-LEHSSKLQL to generate a PI3K inhibitor that was prostate cancer-specific as it contained PSA protease. Meanwhile, it was water-soluble, so it had a higher efficiency to inhibit the PI3K/AKT pathway thereby suppressing prostate cancer growth (52). In addition, a novel hydrophobic and lipophilic and other flavonoid analogs were synthesized that were more active and effective $(47,95)$.

Combination with other substances. Combination therapy has the advantages of increased anticancer effect, lower drug dose, reduced side effects thus benefiting patients. Thus, drug combination therapy has been attracting more and more attention. We investigated the anticancer effect of quercetin combined with 2-methoxyestradiol (2-ME) in both PC-3 and LNCaP cells and found that the combination significantly arrested the cell cycle in the G2/M phase and decreased the $\mathrm{Bcl}-2 / \mathrm{Bax}$ ratio exhibiting synergistic anti-proliferative and pro-apoptotic activities. The study raised the possibility of its use as a new clinically relevant treatment regimen for prostate cancer (4).

Quercetin combined with green tea could produce a synergistical effect in vitro inhibiting proliferation, arresting the cell cycle and inducing apoptosis in PC-3 cells. As in LNCaP cells, they exhibited an additive effect causing stronger anti-proliferative activity than single drug use (35). When used in vivo, the combination of quercetin $(\mathrm{Q})$ and green tea (GT) inhibited prostate cancer xenograft tumor growth by $45 \%$, more effective than quercetin or green tea alone; the inhibition rate of which was $15 \%(0.4 \% \mathrm{Q})$ and $21 \%(\mathrm{GT})$, respectively (88). TRAIL-induced apoptosis in prostate cancer was enhanced when it was combined with quercetin through increased expression and stability of DR5 (29) and decreased survivin (30) or AKT dephosphorylation (31). In vitro, quercetin was combined with epigallocatechin gallate (EGCG) to inhibit prostate cancer stem cell invasion (73) and CWR22Rv1 prostate cancer cell proliferation (48), with kaempferol to induce immunotherapeutic effects (78), with resverol to reduce AR expression (44) and with DNA-damaging drugs (22) plus other dietary phytoestrogens (23). In vivo, quercetin was combined with tamoxifen to inhibit the volume of CWR22 prostate cancer cell xenograft tumors by $73.3 \%$ (87), and with finasteride to significantly decrease prostate weight (89).

Other effective measures. When quercetin was combined with heat treatment in prostate cancer PC-3, LNCaP and JCA-1 cell lines, due to the reduction in HSP70 or HSP72 protein expression and decreased tolerance of cells to heat treatment, it greatly enhanced the heat-induced inhibitory impact on proliferation and the stimulative effect on apoptosis in prostate cancer $(81,82)$. Notably, low-frequency ultrasound sensitized prostate cancer cells to quercetin therapy and increased its inhibitory effect, although the reason remained unclear (96).

\section{Chemopreventive effects and relevant mechanisms}

At present, no effective measures such as biomarkers or radiological techniques exist for the early diagnosis of prostate cancer. Although active surveillance has been studied and tried since 1995 (97), the situation has not shown much improvement. Moreover, an autopsy study of prostate histological analysis of young male patients showed that when in their 20 's, $9 \%$ were found with prostatic intraepithelial neoplasia (PIN), and when in their 30's, 27\% were found with prostate carcinoma (98). Another prostate cancer prevention trial demonstrated that $15.2 \%$ (449 in 2,950) of men were finally diagnosed with prostate cancer even though PSA and digital rectal examination were normal (99). Undiagnosed prostate cancer gradually 
developes to advanced or metastatic stage and becomes an incurable disease with extreme morbidity and a high mortality rate that results in $75 \%$ of patients succumbing to the disease within 5 years. Even if prostate cancer is detected at the early stage, the treatment causes great burden to both the state and individuals. Therefore, prostate cancer prevention has become particularly important to solve these problems and has attracted broad attention (100).

Prostate cancer is an ideal disease for chemoprevention due to its high incidence rate, long course and slow progression (101). It has been widely recognized that men in the United States and other Western countries suffer from a higher incidence rate of prostate cancer than ones living in Eastern countries (102). However, when Oriental men immigrate to the US, adopting a Western diet and life style, the morbidity rate becomes comparable with men living there from birth (103). This evidence powerfully indicates that elements in the diet can influence the occurrence of prostate cancer (48). Epidemiologic studies show that the difference lies in the flavonoid content and higher intake results in lower prostate cancer risk (25). Quercetin is a most common and abundant natural flavonoid and more and more studies are currently focusing on its chemopreventive effects on prostate cancer.

Sharmila et al explored the chemopreventive effects of quercetin on prostate cancer using an in vivo model. Quercetin of $200 \mathrm{mg} / \mathrm{kg}$ was administered to a cancer-induced group and lasted for 16 weeks. At the end of the experiment, it was found that quercetin significantly increased antioxidant enzymes [superoxide dismutase (SOD), catalase (CAT)] and apoptotic proteins (Bax), and decreased IGFIR, AKT and AR. The authors concluded that quercetin could serve as a chemopreventive agent in prostate cancer in a preclinical model by decreasing cell survival and proliferative proteins and promoting apoptosis (5). Sharmila et al in other in vivo experiments drew roughly the same conclusion that quercetin prevented hormone and carcinogen-induced prostate cancer in Sprague-Dawley rats (7) and the chemopreventive effect was realized by decreased levels of proteins of EGFR, PI3K/AKT signaling pathway and cell adhesion molecules (6).

Mechanisms of the chemopreventive effects of quercetin were further investigated in human prostate cancer cell line 22Rv1 and normal human prostate epithelial PrEC cells, and it was ascribed to the possible following alterations: inhibition of cell proliferation by decreasing intracellular $\mathrm{H}_{2} \mathrm{O}_{2}$ and counteracting with peroxiredoxin (Prx) I and II, and preventing oxidative damage by interacting directly with reactive oxygen species (ROS) (104). In primary prostate epithelial cells, quercetin delayed DNA synthesis and reduced AR and its inducible elements, the discovery of which may make physiological chemoprevention of prostate cancer by quercetin a reality (49).

\section{Clinical trails}

Although many in vitro and a few in vivo studies have exhibited many inspiring results of quercetin for antagonizing prostate cancer, they cannot be directly applied to the clinic. Therefore, clinical trails are urgently needed.

Pharmacokinetics of quercetin in the human body has been studied in 1975 and $1996(105,106)$. With the increase in quercetin taken orally by humans, the plasma concentration of quercetin rose in a dose-dependent manner (107). Quercetin has been confirmed to have no genotoxicity in male rats (108). Recently, in two other clinical studies, quercetin (500 mg) was taken twice daily by patients with III chronic prostatitis or $1,000 \mathrm{mg}$ daily by healthy adults, and it was well tolerated by humans and no drug-related toxicity or side effects were observed $(109,110)$. As for a prostate cancer clinical trail, a case control study was carried out in 433 men with primary prostate cancer histologically confirmed and 538 populationbased controls. It was found that the risk for prostate cancer was reduced by $27 \%$ for those who had an intake of at least $24 \mu \mathrm{g}$ of quercetin every day. The odd ratio was $0.64[95 \%$ confidence interval (CI): 0.44-0.92] (111).

\section{Clinical application potential of quercetin for prostate cancer}

As stated above, in vitro studies have verified that quercetin effectively inhibits the growth of various prostate cancer cell lines. When applied in vivo, quercetin inhibits prostate cancer xenograft tumor growth as well. Although the concrete mechanisms investigated vary and there exist only a few preclinical trails, the results are very promising. Clinical trails will provide direct evidence and finally enable quercetin to be applied in the clinic. The pharmacokinetics of quercetin has been studied in the human body and a clinical case control study showed that quercetin reduced the risk of prostate cancer by $27 \%$. In addition, prostate cancer can be chemoprevented by quercetin. Epidemiologic studies indicate that a diet rich in quercetin results in lower prostate cancer risk, and some in vivo experiments in animals have also verified the chemopreventive effect of quercetin on prostate cancer. What is more, quercetin is widely found in the daily diet, is nontoxic and can be easily reaped.

In view of the high incidence rate and the lack of satisfactory comprehensive treatment of prostate cancer, quercetin should be widely accepted and used for clinical treatment. It will not only help decline the incidence rate and improve the adverse effects of prostate cancer treatment, but also offer more benefits to patients and alleviate the great burden for both the state and prostate cancer patients.

\section{Conclusion}

Quercetin, an abundant naturally occurring flavonoid compound, demonstrates great chemotherapeutic and chemopreventive effects for prostate cancer through several different mechanisms. Some clinical trails have verified that quercetin obviously reduces the risk of prostate cancer and is well tolerated by humans even at large doses. However, further clinical trails concerning the therapeutic and preventive effect of quercetin on human prostate cancer are warranted and will provide us with reliable evidence. To improve the bioavailability and absorption and the utilization ratio of quercetin in the human body, further exploration and research is needed.

\section{Acknowledgements}

This study was supported by the Beijing Natural Science Foundation (no. 7122075). 


\section{References}

1. Siegel R, Ma J, Zou Z and Jemal A: Cancer statistics, 2014. CA Cancer J Clin 64: 9-29, 2014.

2. Qu S, Wang K, Xue H, Wang Y, Wu R, Liu C, Gao AC, Gout PW, Collins CC and Wang Y: Enhanced anticancer activity of a combination of docetaxel and Aneustat (OMN54) in a patient-derived, advanced prostate cancer tissue xenograft model. Mol Oncol 8: 311-322, 2014.

3. Xing N, Chen Y, Mitchell SH and Young CY: Quercetin inhibits the expression and function of the androgen receptor in $\mathrm{LNCaP}$ prostate cancer cells. Carcinogenesis 22: 409-414, 2001.

4. Wang G, Song L, Wang H and Xing N: Quercetin synergizes with 2-methoxyestradiol inhibiting cell growth and inducing apoptosis in human prostate cancer cells. Oncol Rep 30: 357-363, 2013.

5. Sharmila G, Bhat FA, Arunkumar R, Elumalai P, Raja Singh P, Senthilkumar K and Arunakaran J: Chemopreventive effect of quercetin, a natural dietary flavonoid on prostate cancer in in vivo model. Clin Nutr 33: 718-726, 2014.

6. Firdous AB, Sharmila G, Balakrishnan S, RajaSingh P, Suganya S, Srinivasan N and Arunakaran J: Quercetin, a natural dietary flavonoid, acts as a chemopreventive agent against prostate cancer in an in vivo model by inhibiting the EGFR signaling pathway. Food Funct 5: 2632-2645, 2014.

7. Sharmila G, Athirai T, Kiruthiga B, Senthilkumar K, Elumalai P, Arunkumar R and Arunakaran J: Chemopreventive effect of quercetin in $\mathrm{MNU}$ and testosterone induced prostate cancer of Sprague-Dawley rats. Nutr Cancer 66: 38-46, 2014.

8. Fleshner N: Defining high-risk prostate cancer: current status Can J Urol (Suppl 1): 14-96, 2005.

9. Hotte SJ and Saad F: Current management of castrate-resistant prostate cancer. Curr Oncol 17 (Suppl 2): S72-S79, 2010.

10. Tannock IF, de Wit R, Berry WR, Horti J, Pluzanska A, Chi KN, Oudard S, Théodore C, James ND, Turesson I, et al; TAX 327 Investigators: Docetaxel plus prednisone or mitoxantrone plus prednisone for advanced prostate cancer. N Engl J Med 351: 1502-1512, 2004.

11. Antonarakis ES and Eisenberger MA: Phase III trials with docetaxel-based combinations for metastatic castration-resistant prostate cancer: time to learn from past experiences. J Clin Oncol 31: 1709-1712, 2013.

12. McKeage K: Docetaxel: a review of its use for the first-line treatment of advanced castration-resistant prostate cancer. Drugs 72: 1559-1577, 2012.

13. Bischoff SC: Quercetin: potentials in the prevention and therapy of disease. Curr Opin Clin Nutr Metab Care 11: 733-740, 2008.

14. Graefe EU, Wittig J, Mueller S, Riethling AK, Uehleke B, Drewelow B, Pforte H, Jacobasch G, Derendorf H and Veit M: Pharmacokinetics and bioavailability of quercetin glycosides in humans. J Clin Pharmacol 41: 492-499, 2001

15. Walle T, Otake Y, Walle UK and Wilson FA: Quercetin glucosides are completely hydrolyzed in ileostomy patients before absorption. J Nutr 130: 2658-2661, 2000.

16. Russo GL, Russo M and Spagnuolo C: The pleiotropic flavonoid quercetin: from its metabolism to the inhibition of protein kinases in chronic lymphocytic leukemia. Food Funct 5: 2393-2401, 2014

17. Kim GT, Lee SH, Kim JI and Kim YM: Quercetin regulates the sestrin 2-AMPK-p38 MAPK signaling pathway and induces apoptosis by increasing the generation of intracellular ROS in a p53-independent manner. Int J Mol Med 33: 863-869, 2014.

18. Chan ST, Yang NC, Huang CS, Liao JW and Yeh SL: Quercetin enhances the antitumor activity of trichostatin A through upregulation of $\mathrm{p} 53$ protein expression in vitro and in vivo. PLoS One 8: e54255, 2013.

19. Piao S, Kang M, Lee YJ, Choi WS, Chun YS, Kwak C and Kim HH: Cytotoxic effects of escin on human castration-resistant prostate cancer cells through the induction of apoptosis and G2/M cell cycle arrest. Urology 84: 982.e1-7, 2014.

20. Mehta RG, Murillo G, Naithani R and Peng X: Cancer chemoprevention by natural products: how far have we come? Pharm Res 27: 950-961, 2010.

21. Liu KC, Yen CY, Wu RS, Yang JS, Lu HF, Lu KW, Lo C, Chen HY, Tang NY, Wu CC, et al: The roles of endoplasmic reticulum stress and mitochondrial apoptotic signaling pathway in quercetin-mediated cell death of human prostate cancer PC-3 cells. Environ Toxicol 29: 428-439, 2014.
22. Samuel T, Fadlalla K, Mosley L, Katkoori V, Turner T and Manne U: Dual-mode interaction between quercetin and DNA-damaging drugs in cancer cells. Anticancer Res 32: 61-71, 2012.

23. Kumar R, Verma V, Jain A, Jain RK, Maikhuri JP and Gupta G: Synergistic chemoprotective mechanisms of dietary phytoestrogens in a select combination against prostate cancer. J Nutr Biochem 22: 723-731, 2011.

24. Noori-Daloii MR, Momeny M, Yousefi M, Shirazi FG, Yaseri M, Motamed N, Kazemialiakbar N and Hashemi S: Multifaceted preventive effects of single agent quercetin on a human prostate adenocarcinoma cell line (PC-3): implications for nutritional transcriptomics and multi-target therapy. Med Oncol 28: 1395-1404, 2011.

25. Haddad AQ, Venkateswaran V, Viswanathan L, Teahan SJ, Fleshner NE and Klotz LH: Novel antiproliferative flavonoids induce cell cycle arrest in human prostate cancer cell lines. Prostate Cancer Prostatic Dis 9: 68-76, 2006.

26. Knowles LM, Zigrossi DA, Tauber RA, Hightower C and Milner JA: Flavonoids suppress androgen-independent human prostate tumor proliferation. Nutr Cancer 38: 116-122, 2000.

27. Kampa M, Hatzoglou A, Notas G, Damianaki A, Bakogeorgou E, Gemetzi C, Kouroumalis E, Martin PM and Castanas E: Wine antioxidant polyphenols inhibit the proliferation of human prostate cancer cell lines. Nutr Cancer 37: 223-233, 2000.

28. Vermeulen K, Van Bockstaele DR and Berneman ZN: Apoptosis: mechanisms and relevance in cancer. Ann Hematol 84: 627-639, 2005.

29. Jung YH, Heo J, Lee YJ, Kwon TK and Kim YH: Quercetin enhances TRAIL-induced apoptosis in prostate cancer cells via increased protein stability of death receptor 5. Life Sci 86: 351-357, 2010.

30. Kim YH, Lee DH, Jeong JH, Guo ZS and Lee YJ: Quercetin augments TRAIL-induced apoptotic death: involvement of the ERK signal transduction pathway. Biochem Pharmacol 75: 1946-1958, 2008.

31. Kim YH and Lee YJ: TRAIL apoptosis is enhanced by quercetin through Akt dephosphorylation. J Cell Biochem 100: 998-1009, 2007.

32. Lee DH, Szczepanski M and Lee YJ: Role of Bax in quercetin-induced apoptosis in human prostate cancer cells. Biochem Pharmacol 75: 2345-2355, 2008.

33. Senthilkumar K, Elumalai P, Arunkumar R, Banudevi S, Gunadharini ND, Sharmila G, Selvakumar K and Arunakaran J: Quercetin regulates insulin like growth factor signaling and induces intrinsic and extrinsic pathway mediated apoptosis in androgen independent prostate cancer cells (PC-3). Mol Cell Biochem 344: 173-184, 2010.

34. Xu R, Zhang Y, Ye X, Xue S, Shi J, Pan J and Chen Q: Inhibition effects and induction of apoptosis of flavonoids on the prostate cancer cell line PC-3 in vitro. Food Chem 138: 48-53, 2013.

35. Wang P, Heber D and Henning SM: Quercetin increased the antiproliferative activity of green tea polyphenol (-)-epigallocatechin gallate in prostate cancer cells. Nutr Cancer 64: 580-587, 2012.

36. Vijayababu MR, Kanagaraj P, Arunkumar A, Ilangovan R, Aruldhas MM and Arunakaran J: Quercetin-induced growth inhibition and cell death in prostatic carcinoma cells (PC-3) are associated with increase in p21 and hypophosphorylated retinoblastoma proteins expression. J Cancer Res Clin Oncol 131: 765-771, 2005

37. Shenouda NS, Zhou C, Browning JD, Ansell PJ, Sakla MS, Lubahn DB and Macdonald RS: Phytoestrogens in common herbs regulate prostate cancer cell growth in vitro. Nutr Cancer 49: 200-208, 2004

38. Eder IE, Culig Z, Putz T, Nessler-Menardi C, Bartsch G and Klocker H: Molecular biology of the androgen receptor: from molecular understanding to the clinic. Eur Urol 40: 241-251, 2001.

39. Culig Z, Klocker H, Bartsch G and Hobisch A: Androgen receptors in prostate cancer. Endocr Relat Cancer 9: 155-170, 2002.

40. Devlin HL and Mudryj M: Progression of prostate cancer: multiple pathways to androgen independence. Cancer Lett 274: 177-186, 2009.

41. Culig Z and Bartsch G: Androgen axis in prostate cancer. J Cell Biochem 99: 373-381, 2006.

42. Yuan H, Young CY, Tian Y, Liu Z, Zhang M and Lou H: Suppression of the androgen receptor function by quercetin through protein-protein interactions of Sp1, c-Jun, and the androgen receptor in human prostate cancer cells. Mol Cell Biochem 339: 253-262, 2010. 
43. Ferruelo A, Romero I, Cabrera PM, Arance I, Andrés G and Angulo JC: Effects of resveratrol and other wine polyphenols on the proliferation, apoptosis and androgen receptor expression in LNCaP cells. Actas Urol Esp 38: 397-404, 2014.

44. Yuan H, Pan Y and Young CYF: Overexpression of c-Jun induced by quercetin and resverol inhibits the expression and function of the androgen receptor in human prostate cancer cells. Cancer Lett 213: 155-163, 2004

45. Yuan HQ, Guo HF, He ML, Kong F, Hu XY, Jiang AL, Xu X, Zhang JY and Charles YF: The roles of c-Jun and CBP in the inhibitory effect of quercetin on prostate cancer cells. Yao Xue Xue Bao 41: 819-824, 2006 (In Chinese).

46. Yuan H, Gong A and Young CY: Involvement of transcription factor Sp1 in quercetin-mediated inhibitory effect on the androgen receptor in human prostate cancer cells. Carcinogenesis 26 : 793-801, 2005

47. Britton RG, Horner-Glister E, Pomenya OA, Smith EE, Denton R, Jenkins PR, Steward WP, Brown K, Gescher A and Sale S: Synthesis and biological evaluation of novel flavonols as potential anti-prostate cancer agents. Eur J Med Chem 54: 952-958, 2012

48. Hsieh TC and Wu JM: Targeting CWR22Rv1 prostate cancer cell proliferation and gene expression by combinations of the phytochemicals EGCG, genistein and quercetin. Anticancer Res 29 : 4025-4032, 2009.

49. Morris JD, Pramanik R, Zhang X, Carey AM, Ragavan N Martin FL and Muir GH: Selenium- or quercetin-induced retardation of DNA synthesis in primary prostate cells occurs in the presence of a concomitant reduction in androgen-receptor activity. Cancer Lett 239: 111-122, 2006.

50. Morgan TM, Koreckij TD and Corey E: Targeted therapy for advanced prostate cancer: inhibition of the PI3K/Akt/mTOR pathway. Curr Cancer Drug Targets 9: 237-249, 2009.

51. Cohen MB and Rokhlin OW: Mechanisms of prostate cancer cell survival after inhibition of AR expression. J Cell Biochem 106: 363-371, 2009

52. Baiz D, Pinder TA, Hassan S, Karpova Y, Salsbury F, Welker ME and Kulik G: Synthesis and characterization of a novel prostate cancer-targeted phosphatidylinositol-3-kinase inhibitor prodrug. J Med Chem 55: 8038-8046, 2012

53. Pratheeshkumar P, Budhraja A, Son YO, Wang X, Zhang Z, Ding S, Wang L, Hitron A, Lee JC, Xu M, et al: Quercetin inhibits angiogenesis mediated human prostate tumor growth by targeting VEGFR- 2 regulated AKT/mTOR/P70S6K signaling pathways. PLoS One 7: e47516, 2012.

54. Yu PC, Gu SY, Bu JW and Du JL: TRPC1 is essential for in vivo angiogenesis in zebrafish. Circ Res 106: 1221-1232, 2010.

55. Potente M, Gerhardt $\mathrm{H}$ and Carmeliet P: Basic and therapeutic aspects of angiogenesis. Cell 146: 873-887, 2011.

56. Yancopoulos GD, Davis S, Gale NW, Rudge JS, Wiegand SJ and Holash J: Vascular-specific growth factors and blood vessel formation. Nature 407: 242-248, 2000.

57. Risau W: Mechanisms of angiogenesis. Nature 386: 671-674, 1997.

58. Oh SJ, Kim O, Lee JS, Kim JA, Kim MR, Choi HS, Shim JH, Kang KW and Kim YC: Inhibition of angiogenesis by quercetin in tamoxifen-resistant breast cancer cells. Food Chem Toxicol 48 3227-3234, 2010.

59. Matei D, Schilder J, Sutton G, Perkins S, Breen T, Quon C and Sidor C: Activity of 2 methoxyestradiol (Panzem NCD) in advanced, platinum-resistant ovarian cancer and primary peritoneal carcinomatosis: a Hoosier Oncology Group trial. Gynecol Oncol 115: 90-96, 2009.

60. Chen Y, Li XX, Xing NZ and Cao XG: Quercetin inhibits choroidal and retinal angiogenesis in vitro. Graefes Arch Clin Exp Ophthalmol 246: 373-378, 2008.

61. Lee DH and Lee YJ: Quercetin suppresses hypoxia-induced accumulation of hypoxia-inducible factor-1alpha (HIF-1alpha) through inhibiting protein synthesis. J Cell Biochem 105: 546-553, 2008

62. Shimada M, Hernandez-Gonzalez I, Gonzalez-Robayna I and Richards JS: Paracrine and autocrine regulation of epidermal growth factor-like factors in cumulus oocyte complexes and granulosa cells: key roles for prostaglandin synthase 2 and progesterone receptor. Mol Endocrinol 20: 1352-1365, 2006.

63. Gioeli D, Mandell JW, Petroni GR, Frierson HF Jr and Weber MJ: Activation of mitogen-activated protein kinase associated with prostate cancer progression. Cancer Res 59: 279-284, 1999.

64. Price DT, Della Rocca G, Guo C, Ballo MS, Schwinn DA and Luttrell LM: Activation of extracellular signal-regulated kinase in human prostate cancer. J Urol 162: 1537-1542, 1999.
65. Shimada K, Nakamura M, Ishida E, Kishi M and Konishi N: Roles of p38- and c-jun NH2-terminal kinase-mediated pathways in 2-methoxyestradiol-induced p53 induction and apoptosis. Carcinogenesis 24: 1067-1075, 2003

66. Senthilkumar K, Arunkumar R, Elumalai P, Sharmila G, Gunadharini DN, Banudevi S, Krishnamoorthy G, Benson CS and Arunakaran J: Quercetin inhibits invasion, migration and signalling molecules involved in cell survival and proliferation of prostate cancer cell line (PC-3). Cell Biochem Funct 29: 87-95, 2011.

67. Cox ME, Gleave ME, Zakikhani M, Bell RH, Piura E, Vickers E, Cunningham M, Larsson O, Fazli L and Pollak M: Insulin receptor expression by human prostate cancers. Prostate 69: 33-40, 2009.

68. Nickerson T, Chang F, Lorimer D, Smeekens SP, Sawyers CL and Pollak M: In vivo progression of LAPC-9 and LNCaP prostate cancer models to androgen independence is associated with increased expression of insulin-like growth factor I (IGF-I) and IGF-I receptor (IGF-IR). Cancer Res 61: 6276-6280, 2001.

69. Vijayababu MR, Kanagaraj P, Arunkumar A, Ilangovan R, Dharmarajan A and Arunakaran J: Quercetin induces p53-independent apoptosis in human prostate cancer cells by modulating Bcl-2-related proteins: a possible mediation by IGFBP-3. Oncol Res 16: 67-74, 2006.

70. Vijayababu MR, Arunkumar A, Kanagaraj P and Arunakaran J: Effects of quercetin on insulin-like growth factors (IGFs) and their binding protein-3 (IGFBP-3) secretion and induction of apoptosis in human prostate cancer cells. J Carcinog 5: 10, 2006.

71. Wang S, DeGroff VL and Clinton SK: Tomato and soy polyphenols reduce insulin-like growth factor-I-stimulated rat prostate cancer cell proliferation and apoptotic resistance in vitro via inhibition of intracellular signaling pathways involving tyrosine kinase. J Nutr 133: 2367-2376, 2003.

72. Bhat FA, Sharmila G, Balakrishnan S, Arunkumar R, Elumalai P, Suganya S, Raja Singh P, Srinivasan N and Arunakaran J: Quercetin reverses EGF-induced epithelial to mesenchymal transition and invasiveness in prostate cancer (PC-3) cell line via EGFR/PI3K/Akt pathway. J Nutr Biochem 25: 1132-1139, 2014.

73. Tang SN, Singh C, Nall D, Meeker D, Shankar S and Srivastava RK: The dietary bioflavonoid quercetin synergizes with epigallocathechin gallate (EGCG) to inhibit prostate cancer stem cell characteristics, invasion, migration and epithelial-mesenchymal transition. J Mol Signal 5: 14, 2010.

74. Ko CC, Chen YJ, Chen CT, Liu YC, Cheng FC, Hsu KC and Chow LP: Chemical proteomics identifies heterogeneous nuclear ribonucleoprotein (hnRNP) A1 as the molecular target of quercetin in its anti-cancer effects in PC-3 cells. J Biol Chem 289: 22078-22089, 2014.

75. Ferruelo A, de Las Heras MM, Redondo C, Ramón de Fata F, Romero I and Angulo JC: Wine polyphenols exert antineoplasic effect on androgen resistant PC-3 cell line through the inhibition of the transcriptional activity of COX-2 promoter mediated by NF- $\kappa$ B. Actas Urol Esp 38: 429-437, 2014 (In English and Spanish).

76. Slusarz A, Shenouda NS, Sakla MS, Drenkhahn SK, Narula AS, MacDonald RS, Besch-Williford CL and Lubahn DB: Common botanical compounds inhibit the hedgehog signaling pathway in prostate cancer. Cancer Res 70: 3382-3390, 2010.

77. Nair HK, Rao KV, Aalinkeel R, Mahajan S, Chawda R and Schwartz SA: Inhibition of prostate cancer cell colony formation by the flavonoid quercetin correlates with modulation of specific regulatory genes. Clin Diagn Lab Immunol 11: 63-69, 2004.

78. Bandyopadhyay S, Romero JR and Chattopadhyay N: Kaempferol and quercetin stimulate granulocyte-macrophage colony-stimulating factor secretion in human prostate cancer cells. Mol Cell Endocrinol 287: 57-64, 2008 .

79. Aalinkeel R, Bindukumar B, Reynolds JL, Sykes DE, Mahajan SD, Chadha KC and Schwartz SA: The dietary bioflavonoid, quercetin, selectively induces apoptosis of prostate cancer cells by down-regulating the expression of heat shock protein 90. Prostate 68: 1773-1789, 2008.

80. Jones EL, Zhao MJ, Stevenson MA and Calderwood SK: The 70 kilodalton heat shock protein is an inhibitor of apoptosis in prostate cancer. Int J Hyperthermia 20: 835-849, 2004

81. Nakanoma T, Ueno M, Iida M, Hirata R and Deguchi N: Effects of quercetin on the heat-induced cytotoxicity of prostate cancer cells. Int J Urol 8: 623-630, 2001.

82. Asea A, Ara G, Teicher BA, Stevenson MA and Calderwood SK: Effects of the flavonoid drug quercetin on the response of human prostate tumours to hyperthermia in vitro and in vivo. Int $\mathbf{J}$ Hyperthermia 17: 347-356, 2001. 
83. Vijayababu MR, Arunkumar A, Kanagaraj P, Venkataraman P, Krishnamoorthy G and Arunakaran J: Quercetin downregulates matrix metalloproteinases 2 and 9 proteins expression in prostate cancer cells (PC-3). Mol Cell Biochem 287: 109-116, 2006.

84. Chaudhary A and Willett KL: Inhibition of human cytochrome CYP 1 enzymes by flavonoids of St. John's wort. Toxicology 217: 194-205, 2006

85. Brusselmans K, Vrolix R, Verhoeven G and Swinnen JV: Induction of cancer cell apoptosis by flavonoids is associated with their ability to inhibit fatty acid synthase activity. J Biol Chem 280: 5636-5645, 2005.

86. Huynh H, Nguyen TT, Chan E and Tran E: Inhibition of ErbB-2 and ErbB-3 expression by quercetin prevents transforming growth factor $\alpha$ (TGF- $\alpha$ )- and epidermal growth factor (EGF)-induced human PC-3 prostate cancer cell proliferation. Int J Oncol 23: 821-829, 2003.

87. Ma ZS, Huynh TH, Ng CP, Do PT, Nguyen TH and Huynh H: Reduction of CWR22 prostate tumor xenograft growth by combined tamoxifen-quercetin treatment is associated with inhibition of angiogenesis and cellular proliferation. Int J Oncol 24 1297-1304, 2004.

88. Wang P, Vadgama JV, Said JW, Magyar CE, Doan N, Heber D and Henning SM: Enhanced inhibition of prostate cancer xenograft tumor growth by combining quercetin and green tea. J Nutr Biochem 25: 73-80, 2014

89. Ma Z, Hung Nguyen T, Hoa Huynh T, Tien Do P and Huynh $\mathrm{H}$ Reduction of rat prostate weight by combined quercetin-finasteride treatment is associated with cell cycle deregulation. J Endocrinol 181: 493-507, 2004

90. Xiao ZP, Peng ZY, Peng MJ, Yan WB, Ouyang YZ and Zhu HL: Flavonoids health benefits and their molecular mechanism. Mini Rev Med Chem 11: 169-177, 2011.

91. Szliszka E and Krol W: The role of dietary polyphenols in tumor necrosis factor-related apoptosis inducing ligand (TRAIL)-induced apoptosis for cancer chemoprevention. Eur J Cancer Prev 20: 63-69, 2011.

92. Leonarduzzi G, Testa G, Sottero B, Gamba P and Poli G: Design and development of nanovehicle-based delivery systems for preventive or therapeutic supplementation with flavonoids. Curr Med Chem 17: 74-95, 2010.

93. Klingeler R, Hampel S and Büchner B: Carbon nanotube based biomedical agents for heating, temperature sensoring and drug delivery. Int J Hyperther 24: 496-505, 2008.

94. Cirillo G, Vittorio O, Hampel S, Iemma F, Parchi P, Cecchini M, Puoci F and Picci N: Quercetin nanocomposite as novel anticancer therapeutic: improved efficiency and reduced toxicity. Eur J Pharm Sci 49: 359-365, 2013.

95. Forbes AM, Lin H, Meadows GG and Meier GP: Synthesis and anticancer activity of new flavonoid analogs and inconsistencies in assays related to proliferation and viability measurements. In J Oncol 45: 831-842, 2014.

96. Paliwal S, Sundaram J and Mitragotri S: Induction of cancer-specific cytotoxicity towards human prostate and skin cells using quercetin and ultrasound. Br J Cancer 92: 499-502, 2005 .
97. Lund L, Svolgaard N and Poulsen MH: Prostate cancer: a review of active surveillance. Res Rep Urol 6: 107-112, 2014.

98. Sakr WA, Haas GP, Cassin BF, Pontes JE and Crissman JD: The frequency of carcinoma and intraepithelial neoplasia of the prostate in young male patients. J Urol 150: 379-385, 1993.

99. Thompson IM, Pauler DK, Goodman PJ, Tangen CM Lucia MS, Parnes HL, Minasian LM, Ford LG, Lippman SM, Crawford ED, et al: Prevalence of prostate cancer among men with a prostate-specific antigen level $<$ or $=4.0 \mathrm{ng}$ per milliliter. N Engl J Med 350: 2239-2246, 2004.

100. Ting H, Deep G, Agarwal C and Agarwal R: The strategies to control prostate cancer by chemoprevention approaches. Mutat Res Fundam Mol Mech Mutagen 760: 1-15, 2014

101. Wang Z, Fan J, Liu M, Yeung S, Chang A, Chow MS, Pon D and Huang Y: Nutraceuticals for prostate cancer chemoprevention: from molecular mechanisms to clinical application. Expert Opin Investig Drugs 22: 1613-1626, 2013.

102. Hsing AW, Tsao L and Devesa SS: International trends and patterns of prostate cancer incidence and mortality. Int J Cancer 85: 60-67, 2000.

103. Cook LS, Goldoft M, Schwartz SM and Weiss NS: Incidence of adenocarcinoma of the prostate in Asian immigrants to the United States and their descendants. J Urol 161: 152-155, 1999.

104. Chaudhary A, Pechan T and Willett KL: Differential protein expression of peroxiredoxin I and II by benzo(a)pyrene and quercetin treatment in 22Rv1 and PrEC prostate cell lines. Toxicol Appl Pharmacol 220: 197-210, 2007.

105. Gugler R, Leschik M and Dengler HJ: Disposition of quercetin in man after single oral and intravenous doses. Eur J Clin Pharmacol 9: 229-234, 1975.

106. Ferry DR, Smith A, Malkhandi J, Fyfe DW, deTakats PG, Anderson D, Baker J and Kerr DJ: Phase I clinical trial of the flavonoid quercetin: pharmacokinetics and evidence for in vivo tyrosine kinase inhibition. Clin Cancer Res 2: 659-668, 1996.

107. Egert S, Wolffram S, Bosy-Westphal A, Boesch-Saadatmandi C, Wagner AE, Frank J, Rimbach G and Mueller MJ: Daily quercetin supplementation dose-dependently increases plasma quercetin concentrations in healthy humans. J Nutr 138: $1615-1621,2008$

108. Utesch D, Feige K, Dasenbrock J, Broschard TH, Harwood M Danielewska-Nikiel B and Lines TC: Evaluation of the potential in vivo genotoxicity of quercetin. Mutat Res 654: 38-44, 2008.

109. Shoskes DA, Zeitlin SI, Shahed A and Rajfer J: Quercetin in men with category III chronic prostatitis: a preliminary prospective, double-blind, placebo-controlled trial. Urology 54: 960-963, 1999.

110. Cialdella-Kam L, Nieman DC, Sha W, Meaney MP, Knab AM and Shanely RA: Dose-response to 3 months of quercetin-containing supplements on metabolite and quercetin conjugate profile in adults. Br J Nutr 109: 1923-1933, 2013

111. McCann SE, Ambrosone CB, Moysich KB, Brasure J, Marshall JR, Freudenheim JL, Wilkinson GS and Graham S: Intakes of selected nutrients, foods, and phytochemicals and prostate cancer risk in Western New York. Nutr Cancer 53: $33-41,2005$ 